\title{
Tibet presser Kina - og det giver jordskcelv!
}

\section{Af Tine B. Larsen, GEUS}

Jordens mest spektakulære topografi findes i Asien, hvor høje bjergtinder knejser mod himlen, skabt i sammenstødet mellem Indien og Eurasien over de seneste 50 millioner år. Topografien vedligeholdes løbende af den aktive pladetektonik i området. Den Indiske plade presser sig ubønhørligt nordpå med 4-5 $\mathrm{cm}$ om året, og den Eurasiske plade lader sig ikke uden videre flytte, så undergrunden flænses jævnligt af voldsomme jordskælv, når klipperne må give efter for presset.

D. 12. maj $2008 \mathrm{kl}$. 08:28 dansk tid rystedes det vestlige Kina af et kraftigt jordskælv, som målte 7,9 på Richterskalaen. Jordskælvet havde sit epicenter $90 \mathrm{~km}$ vest-nordvest for byen Chengdu ved den vestlige kant af Sichuan-bassinet. Jordskælvet medførte omfattende tab af menneskeliv og enorme materielle skader. I alt døde 87.652 mennesker som følge af jordskælvet, mere end 15 millioner blev evakueret, og over 5 millioner mistede deres hjem. Ud over store skader i selve Chengdu blev mange mindre byer i området fuldstændigt ødelagt, enten fordi husene bukkede under for rystelserne eller blev begravet af de mange stenskred, der fulgte. Rystelserne fra jordskælvet kunne mærkes langt væk bl.a. i Beijing, Shanghai og Hong Kong. Også i dele af Bangladesh, Taiwan, Thailand og Vietnam kunne rystelserne mærkes.

\section{Store kræfter på spil}

Chengdu ligger langt fra Indien, men det er alligevel i Indien, vi skal finde den overordnede forklaring på jordskælvet. Når den Indiske plade bevæger sig nordpå, skubber Indien det Tibetanske Plateau til siden dvs. mod øst. Herved bliver det Tibetanske Plateau presset ind mod Sichuan-bassinet (se de blå pile på figuren til højre). På grænsen mellem det Tibetanske Plateau og Sichuan-bassinet ligger den store Longmen Shan-forkastning, og det er netop på denne forkastning, at jordskælvet fandt sted. Forkastningen er formodentlig en gammel pladegrænse, der stadig er aktiv.

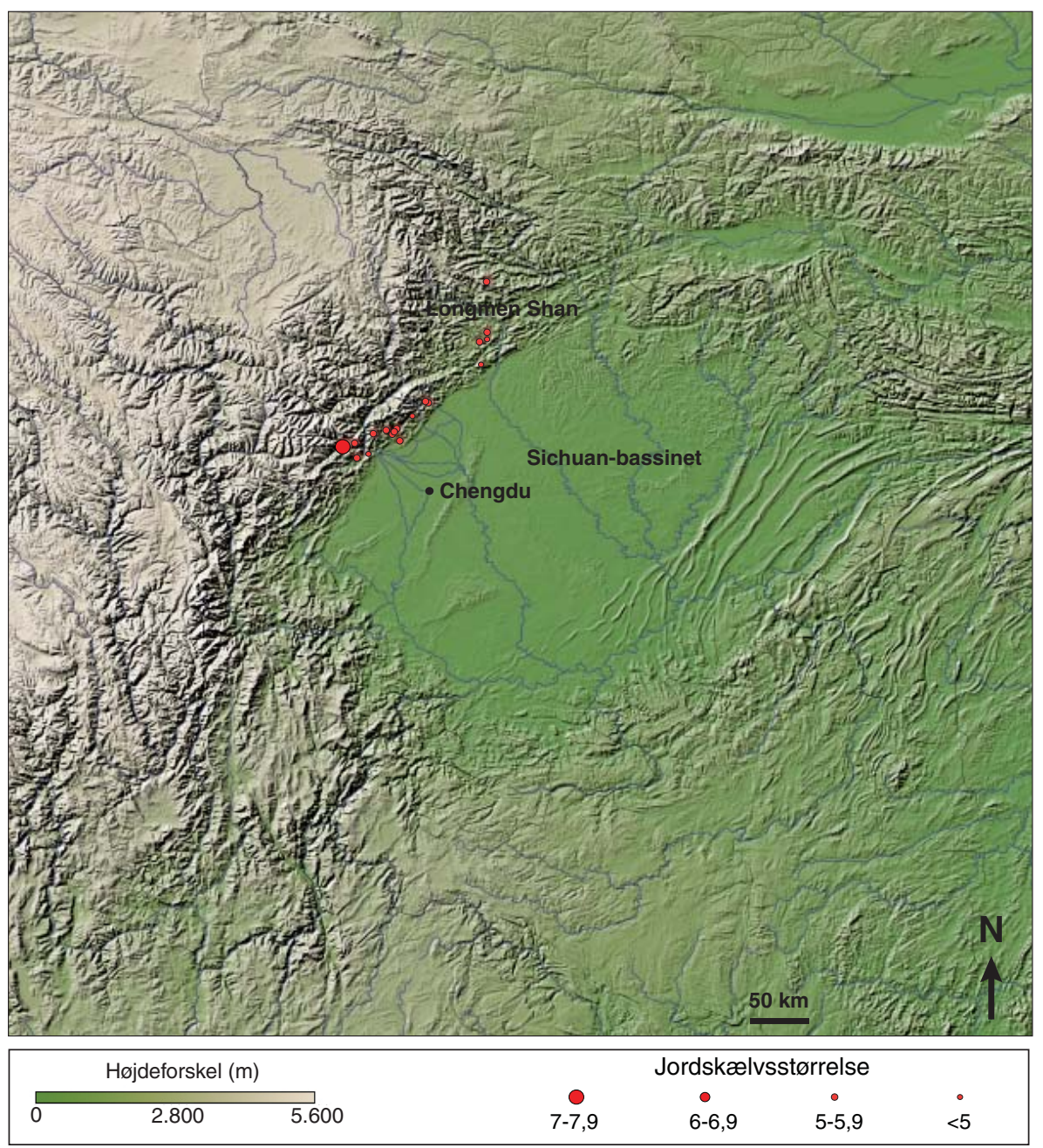

Højdekort over området, hvor jordskcelvet ramte. Den store røde prik læengst mod SV markerer jordskcelvets epicenter og de små røde prikker viser det første døgns efterskcelv. Topografien går fra $0 \mathrm{~m}$ i Sichuan-bassinet til $5.600 \mathrm{~m}$ i Longmen Shan bjergene. (UVH modificeret efter NASA: http://earthobservatory.nasa.gov/NaturalHazards/. Copyright: NASA)

De blå pile viser Indiens bevcegelse nordpå som presser det tibetanske plateau, der presser videre mod øst ind $i$ Sichuan-bassinet. Rystelserne fra jordskcelvet var så kraftige, at de kunne mcrkes i bl.a. Beijing, Shanghai og Hong Kong samt i dele af Bangladesh, Taiwan, Thailand og Vietnam. (Grafik: $U V H)$

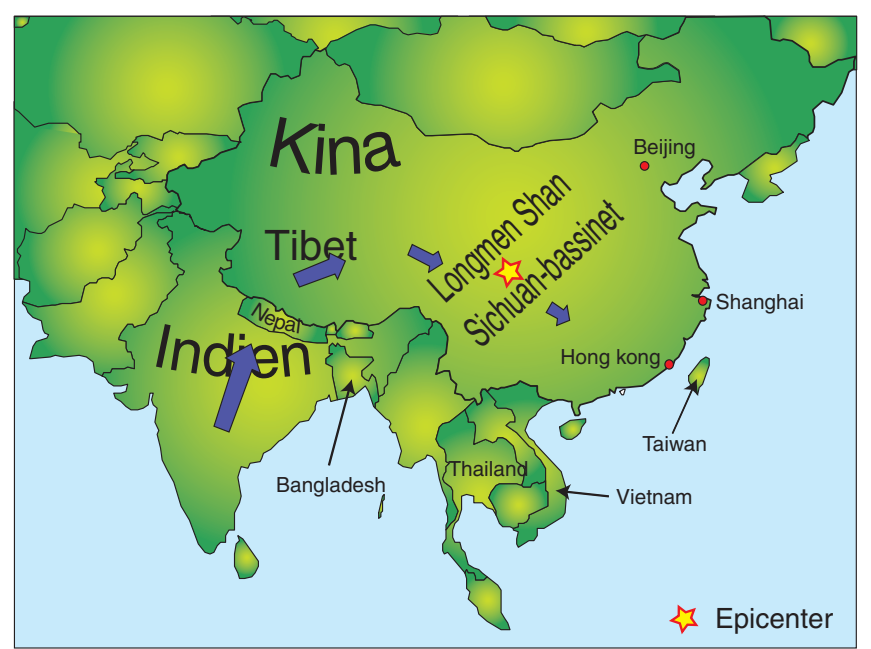




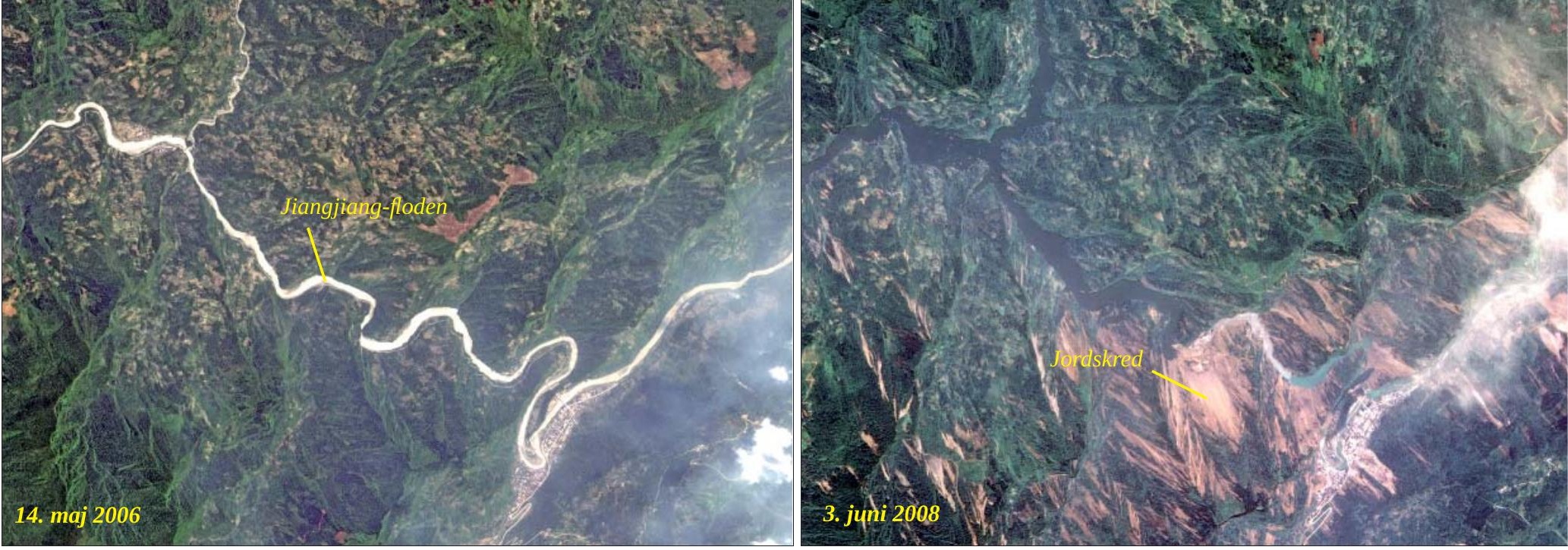

Tangjiashan-søen i det jordskcelvsramte Beichuan-amt. Billedet til højre viser Jianjiang-floden i maj 2006, hvor alt ser normalt ud. Fotoet til højre (i rigtige farver) stammer fra d. 3. juni, hvor Jianjiang-floden er næesten ukendelig. Vandniveauet er kraftigt forhøjet og har taget form efter de stejle bjergsider, som den løber $i$. Vejen, der engang løb langs siden (billedet til venstre), er helt vcek. Et enormt jordskred, der har opdœemmet floden, dcekker flere $100 \mathrm{~m}$ af flodens bugtning. (Foto: Formosat image (c) 2008 Dr. Cheng-Chien Liu, National Cheng-Kung University and Dr. An-Ming Wu, National Space Organization, Taiwan)

Longmen Shan er også navnet på den bjergkæde, som udgør den østligste grænse af det Tibetanske Plateau. Topografien er her ekstrem med stigninger i relieffet på mere end $5 \mathrm{~km}$ over en afstand på blot 50 $\mathrm{km}$. Den nedre skorpe under Longmen Shan er svag og nem at deformere i modsætning til den nedre skorpe under Sichuan-bassinet, som er stærk og bedre kan holde "faconen". Målinger med GPS viser, at Tibet i gennemsnit skubber sig ind over Sichuan-bassinet med $4 \mathrm{~mm}$ pr år. Forskydningerne i forbindelse med jordskælvet kan lokalt have været op til 12 meter ifølge beregninger, men der er endnu ikke kommet nogen målinger ud fra området.

\section{Langvarigt jordskælv}

Et jordskælvs epicenter er det punkt på jordoverfladen, som ligger lige over det sted $i$ undergrunden, hvor jordskælvet starter. Ved små jordskælv er bruddet $i$ undergrundens klipper begrænset til et lille område nær epicentret, og det er hurtigt overstået. Ved Chendu-jordskælvet revnede forkastningszonen over en strækning på mindst $200 \mathrm{~km}$ fra epicentret mod nordøst langs med kanten af bjergene. Det tog ca. 50 sekunder.

Kort tid efter jordskælvet begyndte efterskælvene at ryste området. Det er helt normalt efter et større jordskælv. De største efterskælv målte over 6 på Richterskalaen og forårsagede yderligere ødelæggelser af de i forvejen beskadigede bygninger. Mange efterskælv var også kraftige nok til at starte stenskred. Efter et par uger var de kraftige efterskælv overstået, men flere måneder efter kommer der stadig mindre efterskælv, dog med længere og længere mellemrum.

\section{Hvorfor så slemt?}

Historisk set er det vestlige Sichuan et område med mange jordskælv, og store jordskælv er ikke usædvanlige. Jordskælvet i maj var således det 10. jordskælv inden for mindre end 100 år som målte mindst 7,0 på Richterskalaen. Det seneste jordskælv havde dog de største menneskelige omkostninger.

Et kraftigt jordskælv på 7,9 er altid en alvorlig begivenhed $i$ et befolket område. Jordskælvet i Kina gik dog særligt galt pga. en uheldig kombination af geologiske og kulturelle faktorer: Området er meget tæt befolket, og husene var ikke bygget særligt solidt. Samtidig blev rystelserne forstærket af det tykke lag sedimenter i Sichuan-bassinet. Sedimenterne nøjedes ikke med at forstørre bølgernes amplitude, men fik dem også til at løbe langsommere, hvilket betød at rystelserne varede i længere tid, end de ville have gjort i fast klippe. Områdets voldsomme topografi var også med til at forværre effekterne af jordskælvet, idet store stenskred væltede ned fra de stejle bjergsider og begravede hele landsbyer, væltede broer og blokerede veje. Stenskred blokerede også mange floder, så der opstod faretruende søer, og eksisterende dæmninger kom under pres.

\section{Blev det forudsagt?}

Dagen efter jordskælvet kunne man læse i Berlingske Tidende at jordskælvet var blevet forudsagt for et år siden. Det er imidlertid en overdrivelse, hvis man kræver at en forudsigelse skal indeholde omtrentlig tid og sted for det forventede jordskælv. En gruppe forskere udgav sidste år en videnskabelig artikel med deres undersøgelser af forkastningerne langs Longmen Shan. Forskerne var kommet frem til, at forkast-

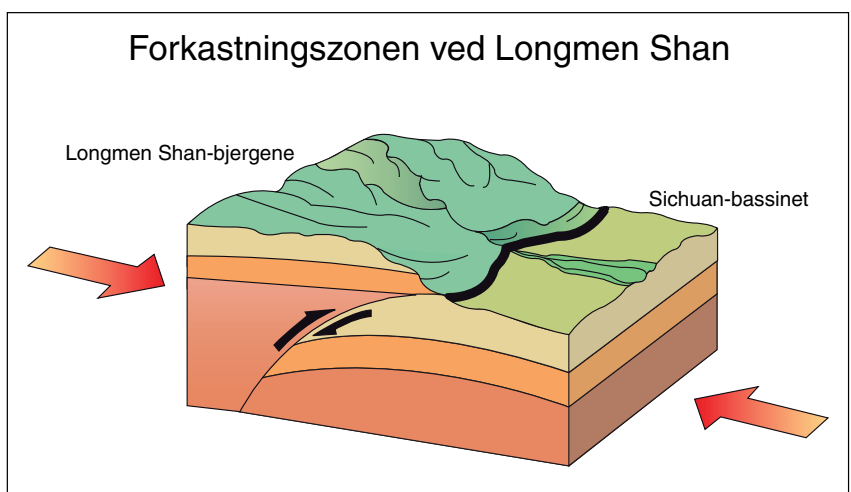

De to landmasser presses mod hinanden, og Longmen Shan-bjergene glider over Sichuan-bassinet. (Grafik: UVH Modificeret efter figur fra http://www.tectonics.caltech.edu/2008MayChinaEQ/ xichuan.html)

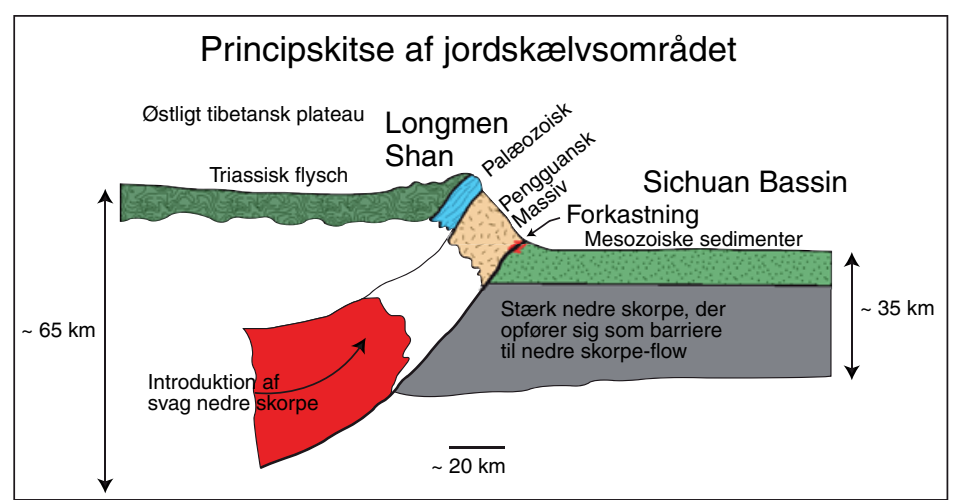

Sichuan-bassinets stcrke skorpe bliver kun lettere deformeret i den voldsomme sammenpresning. I stedet deformeres det tibetanske plateau, der foldes op i de mregtige Longmen Shan-bjerge. (Grafik: UVH Modificeret efter figur fra http://quake.mit.edu/ changli/wenchuan.html) 
ningerne er lange og kraftige nok til at kunne brydes i et stort jordskælv. Forskerne konkluderede også, at forkastningerne udgør en "potentiel alvorlig kilde til seismisk risiko", med andre ord: Disse forkastninger kan være en tikkende bombe!

Det har desværre vist sig at være helt korrekt, selvom der ikke var tale om en egentlig forudsigelse. Der er i stedet tale om en risikovurdering, som seismologer løbende laver for aktive forkastninger over hele Verden. Fx er det almindeligt anerkendt, at der er stor risiko for, at et større jordskælv på et tidspunkt rammer San Francisco, men ingen kan forudsige, hvornår det sker.

\section{Kilde:}

USGS, Tectonics Observatory at Caltech, Dept. of Earth, Atmospheric, and Planetary Sciences at MIT.

Seismogrammer fra GEUS' seismograf $i$ Mønsted Kalkgrube, som viser, hvordan jordskcelvet $i$ Kina får Jorden til at bevæege sig. Det øverste seismogram viser, hvordan Jorden bevceger sig op og ned. Det midterste seismogram viser Jordens bevcegelser i nordsyd-retningen, og det nederste seismogram er en registrering af Jordens bevcegelser $i$ øst-vest-retningen. Det første stykke tid ses kun Jordens svage baggrundsrumlen, men kl. 06:38:54 UTC rammer P-bølgen med fuld kraft. P-bølgen påvirker især Jordens op- og ned-bevcegelser. Efter ca. 10 minutter når den lidt langsommere S-bølge frem. Den giver størst udslag på de horisontale komponenter. Jordskcelvet skete kl. 06:28:00 UTC, så de første rystelser har vcret knap 11 minutter om at nå frem til os. Det viste tidsudsnit er 15 minutter langt. (Grafik: Seismogram fra Mønsted Kalkgrube)

\section{Seismogram fra seismografen i Mønsted Kalkgrube}

Plot start time: $2008 \quad 512 \quad 6: 38 \quad 0.008$

$20085126380 R$ MUD 1

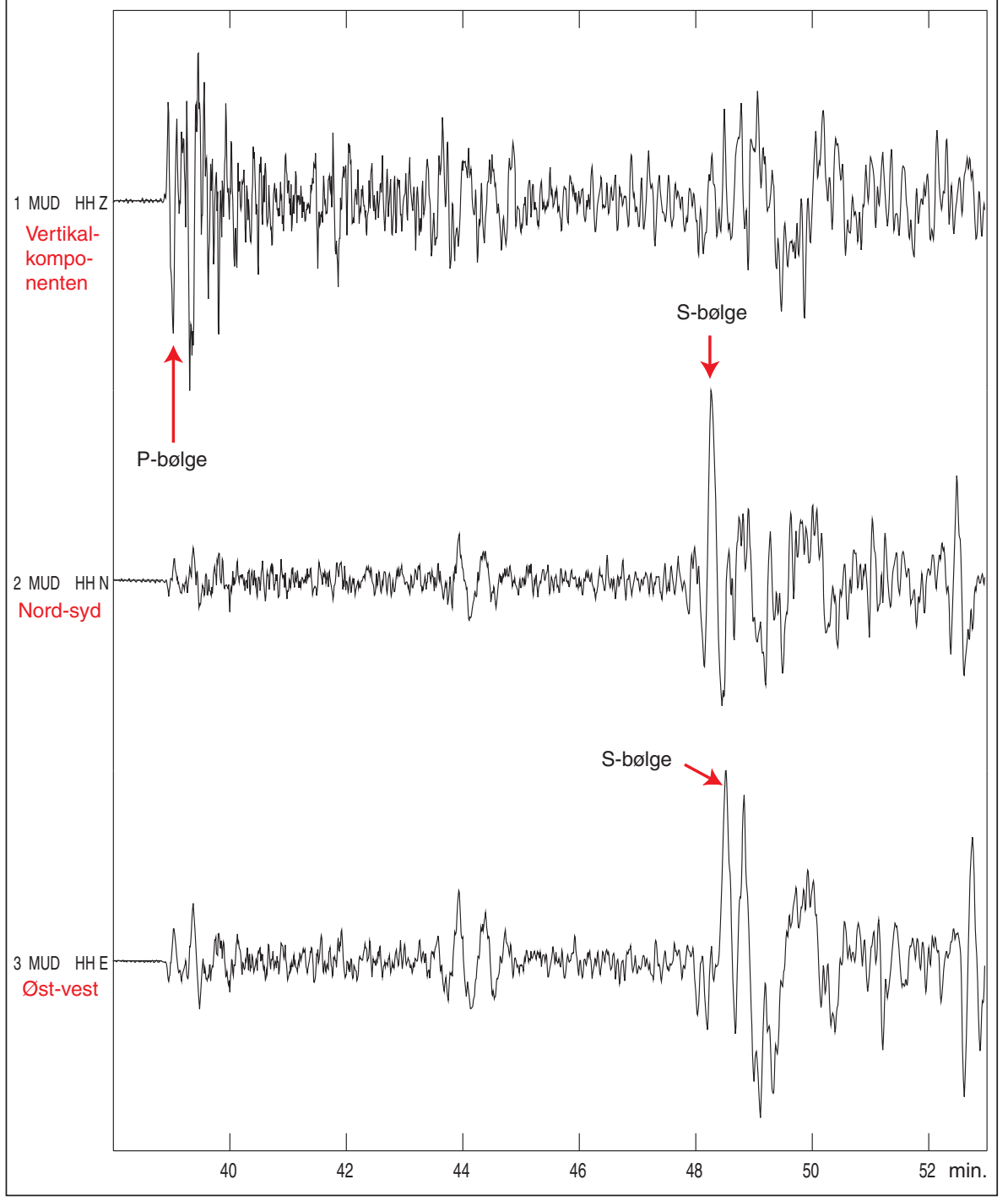

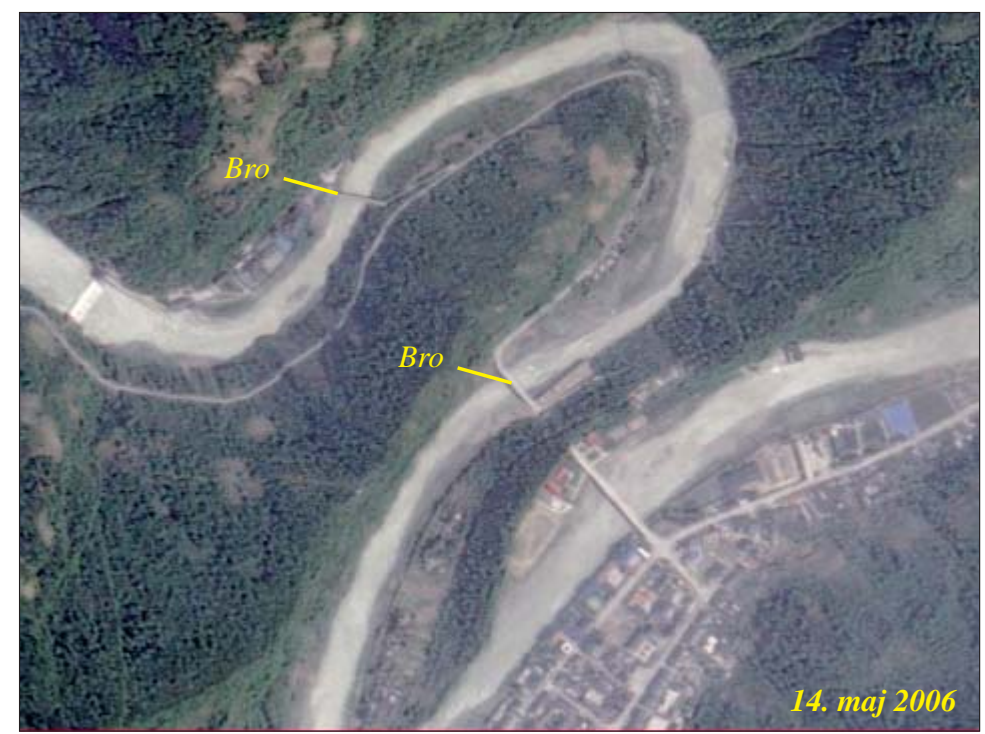

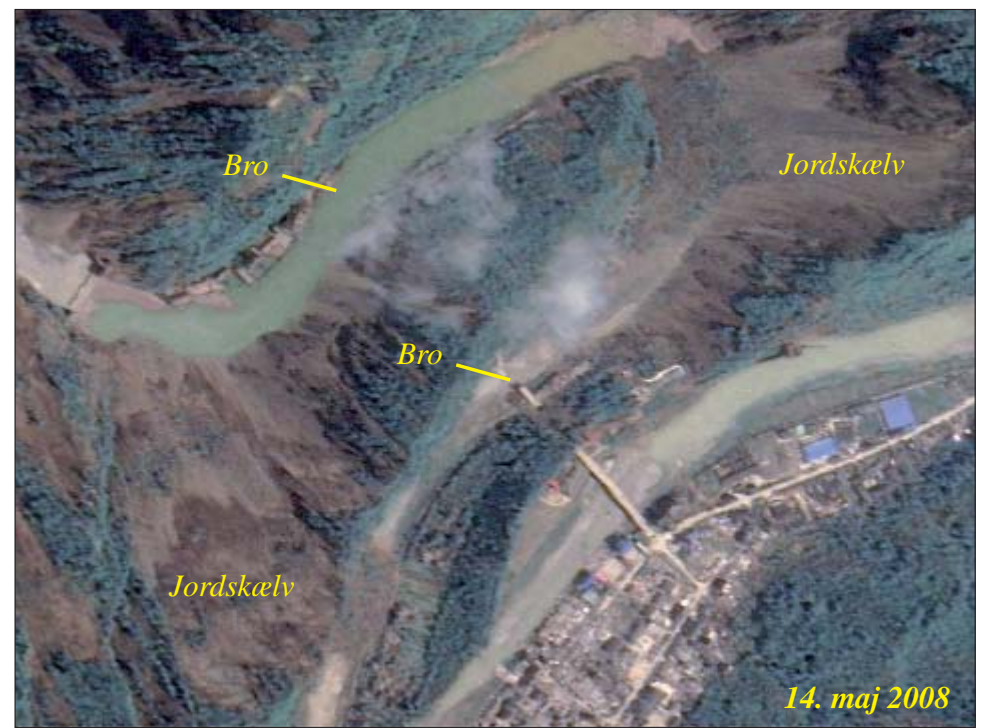

Jordskcelvet d. 12. maj i år forvoldte mange voldsomme skader overalt. Billederne viser det bjergfulde område i Beichuan-amtet. Fotoet til højre fra maj 2006 viser området, som det så ud før jordskcelvet. På fotoet til højre ser man en sammenbrudt bro, en bro der er oversvømmet af en nyligt dannet sø samt adskillige jordskred. (Foto: Formosat image (c) 2008 Dr. Cheng-Chien Liu, National Cheng-Kung University and Dr. An-Ming Wu, National Space Organization, Taiwan) 